\title{
Famílias do mundo ibérico: cotidiano, política e mudanças sociais na Argentina e na Espanha
}

\author{
Janaína Helfenstein
}

NUEVOS TIEMPOS PARA LAS FAMILIAS, FAMILIAS PARA LOS NUEVOS TIEMPOS Do las sociodados tradicionalos a las sociodades burguesass perspectivas comparadas entre Argentina y España

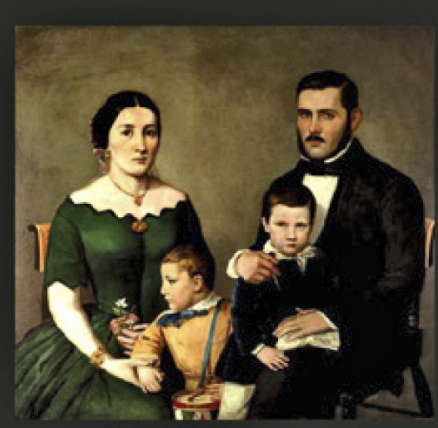


Lançado em agosto de 2016 em Córdoba, Argentina, durante o II Congreso Internacional de Familias y Redes Sociales, o livro Nuevos tiempos para las familias, familias para los nuevos tempos. De las sociedades tradicionales a las sociedades burguesas: perspectivas comparadas entre Argentina y España, organizado pelos professores Mónica Chirardi e Antonio Irigoyen Lopez, reúne uma série de textos produzidos por pesquisadores argentinos e espanhóis dedicados aos estudos relacionados à História da Família e à Demografia Histórica.

Mónica Chirardi é professora titular no Centro de Estudos Avançados da Faculdade de Ciências Sociais da Universidad de Córdoba. É especialista em História do Casamento e da Família, sexualidade, gênero, miscigenação e escravidão, sendo esses aspectos analisados na obra pela perspectiva sociocultural e demográfica.

Antonio Irigoyen Lopez é professor de História Moderna na Universidad de Murcia, na Espanha, especializado em História Social da Igreja e do Clero na monarquia hispânica durante os séculos XVI a XVIII. Suas pesquisas se concentram na cerimônia matrimonial e sua regulação eclesiástica, como também no batismo e nas relações de compadrio.

A obra em questão está estruturada em um texto introdutório, produzido pelos organizadores, e mais cinco capítulos, todos pautados por uma análise comparativa entre Espanha e Argentina, e produzidos em pares, sendo um autor de cada nacionalidade. 0 livro adota como perspectiva a história comparada, buscando encontrar e identificar similitudes e contrastes na vida cotidiana das famílias do mundo ibérico, com ênfase em Córdoba, na Argentina, e Múrcia, na Espa- nha, centrando sua análise na identificação das particularidades dos processos de mudança social ocorridas nessas duas localidades.

Para os autores, a partir da investigação das mudanças na estrutura familiar, nos comportamentos e nas expectativas de seus componentes, é possível avançar nos conhecimentos que temos a respeito das mudanças sociais. Ainda na introdução, os organizadores enfatizam que é fundamental interrogar-se sobre o desenvolvimento do individualismo tendo em mente que este é um processo de afirmação pessoal, mas que caminha paralelamente às mudanças que ocorrem na família, pensada como instituição social. Assim, a História da vida cotidiana ocupa-se das condições de vida dos seres humanos a partir da coletividade, mas sem deixar de pensar nas particularidades e singularidades dos indivíduos. Devemos, portanto, concentrar-nos no componente duplo que existe nesse âmbito, 0 individual versus o coletivo, ou nos vínculos sociais versus laços pessoais, e para que possamos detectar as mudanças que ocorrem nesses universos e os fenômenos que os levam a acontecer "existe um lugar privilegiado que exerce as vezes de laboratório: a fámília" (p. 9, tradução livre).

A obra possui cinco capítulos que abrangem desde os comportamentos e dinâmicas familiares até as mudanças ocorridas com os indivíduos no interior das famílias. O primeirò capítulo, intitulado Familia y poder político en las periferias de la Monarquía Hispánica (Reino de Murcia y Córdoba del Tucumán en tiempos de los Austrias), de autoria de Francisco Izquierdo e Federico Sartori, se concentra no século XVII e tem como objetivo apresentar os comportamentos e as dinâmicas 
familiares de duas famílias da elite de dois territórios distintos e geograficamente distantes, mas que, de acordo com os autores, estão vinculados por uma mesma condição periférica: no caso de Córdoba del Tucumán, uma localidade pertencente a um virreinato ${ }^{7}$ da Espanha no Continente Americano, e no caso de Múrcia, um reino peninsular espantiol.

Neste primeiro capítulo, os autores demonstram como os estudos das famílias de elite são importantes para a compreensão das características das sociedades de Antigo Regime e, ao colocarem Família e Poder Político como elementos de um "binômio necessário", deixam claro como as relações familiares nesse período ultrapassam os limites do privado e do domiciliar para se firmarem no âmbito das estratégias políticas.

O segundo capítulo, de Juan Francisco López e María del Carmen Ferreyra, Matrimonio y dispensas matrimoniales en Iberoamérica. Estudio comparado en las provincias de Córdoba y Murcia, diz respeito ao casamento realizado entre parentes, que em teoria era proibido pela Igreja Católica. No entanto, havia uma forma de validação desta união através das dispensas matrimoniais. Os autores se dedicaram em demonstrar como os casamentos consanguíneos poderiam ser meios de estabelecer alianças sociais e políticas nos territórios espanhóis, assim como na Europa e na América. Todavia, com uma diferença bastante notável: a prática nos territórios hispânicos era muito desigual da encontrada nos territórios americanos. Enquanto na Europa o processo era mais complexo, nas Américas era obtido de forma muito mais simples, em

1 Os virreinatos eram entidades territoriais estabelecidas pela coroa Espanhola em suas colônias na América. Córdoba del Túcunmán pertencia ao Virreinato del Perú. virtude da distância e lentidão de envio da documentação para Roma.

Indumentaria masculina en transición. Un aná-, lisis comparativo entre Madrid-Murcia (España) y Córdoba (Argentina), siglos XVIII-XIX, de Cecilia Moreyna e Arianna Giorgi, é o terceiro capítulo da obra e teve por objetivo observar, analisar e interpretar a vestimenta elitista como um elemento que marca a transição de uma sociedade tradicional de Antigo Regime para uma sociedade moderna. As autoras verificaram que, nesse período, os trajes utilizados pelos homens de elite hispânica passaram a ter uma função para além da usual: não somente de cobrir os corpos, como também de distinção social, sobretudo no território Ibero-americano.

O quarto capítulo do livro, Los discursos sobre la família católica en la prensa religiosa de inicios del siglo XX, de Francisco Sánchez e Sara Moyano, se dedica a responder questões como: "Qual espaço a família ocupou nos meios de imprensa religiosa do início do século XX?"; "O que a Igreja Católica dizia a respeito da família?"; ou ainda, "O discurso da imprensa católica era semelhante nos territórios distantes de Murcia e Córdoba?". Segundo as autoras, o discurso era semelhante e estava pautado em demonstrár que a família era a pedra fundamental para a sustentação de um modelo social em que a Igreja determinava os comportamentos. Portanto, as mudanças sociais que afetavam esse modelo eram consideradas como uma ameaça à'sociedade católica.

O quinto e último capítulo foi escrito pelos organizadores da obra e se intitula De la família del linaje a la família de los individuos. Unidad y diversidad de los procesos de cambio histórico a ambos lados del Atlántico. Este capítulo 
teve por objetivo apresentar as transformações da instituição familiar nos territórios da monarquia hispânica, buscando, a partir de uma análise comparativa de Espanha e Argentina, as similaridades nos processos de transição e mudanças sociais a partir do casamento e das relações de parentesco entre esses dois territórios.

Como se pode verificar a partir desse pequeno resumo dos capítulos, a obra em questão apresenta relevantes temáticas do campo de estudos da História da Família. Todavia, o tema que teve mais destaque nesse livro foi o das estratégias familiares, mais precisamente, as estratégias, arranjos e redes que as famílias da elite ibérica estruturavam e tramavam com a finalidade de ascensão social e manutenção do poder adquirido.

A família, como poderemos ver a seguir, é ao mesmo tempo meio de se obter prestígio e também palco das alianças necessárias para se alcançar tal prestígio. Para tanto, na maioria das vezes o matrimônio é o principal. mecanismo para transformar em efetivo e indissolúvel o vínculo de união entre famílias: "Tais uniões contribuiriam para definir um ninho de relações com famílias bem açomodadas [...], o que garantia um mínimo de espaço de poder suficiente para tecer alianças e ter acesso a novas redes fundamentais para reforçar sua posição política" (p. 33-34, tradução livre):

Muito mais que um sacramento divino, o ato de casar-se era também político, estratégico e extremamente avaliado. Assim sendo, até mesmo os casamentos realizados com os membros da própria família eram mais corriqueiros do que pensamos.

Essa questão das estratégias familiares e das alianças políticas tecidas através dos arranjos matrimoniais foi bem exemplificada a partir da leitura dos capítulos 7 e 2 do livro. Izquierdo e Sartori, no primeiro capítulo, demons-, tram a partir de suas pesquisas que, mesmo em territórios distintos, e até em universos políticos um pouco diferentes - como Múrcia, localizada na Espanha, e Córdoba del Tucumán, localizada na Argentina, metrópole e colônia -, as estratégias para se conseguir prestígio não eram tão diferenciadas.

Los Macanaz, a família murciana apresentada, era uma família mediana, sem muitos patrimônios - segundo os autores - mas que tinha como objetivo conseguir cargos de prestígio junto ao conselho local, pois esta seria uma maneira mais efetiva de se enraizar na região. Para esta família "a maior parte das núpcias estarão orientadas a reforçar suas expectativas de acesso e consolidação no reduzido colégio político da localidade, forjando para si uma rede de famílias próximas de relativo peso e tradição política" (p.32, tradução livre). Los Macanaz objetivavam então, através do casamento de seus filhos e filhas, manter relações com famílias importantes no cenário político local, ampliando sua base de parentesco ao se inserir em novos grupos familiares que pudessem apoiar e, sobretudo, reforçar suas aspirações.

Por outro lado, Los de Cámara, de Córdoba, na Argentina, iniciaram sua linhagem em uma recém-fundada cidade no território espanhol nas Américas. Assim, para eles era fundamental consolidar a família a partir da posse da terra, posse de escravos e dos acessos aos cargos do governo e, com isso, se inserir na sociedade criolla. Córdoba está localizada em uma região geográfica estratégica, o que fazia da cidade um ponto de comunicação de todo o território. Além disso, 
possuía um bom, desenvolvimento agrícola e pecuário (gado bovino e muar) e, sobretudo, indígenas que trabalhavam sob o regime de encomenda, o que permitiu o rápido fortalecimento econômico da região. Segundo os autores, as elites dessa região seriam um grupo reduzido de famílias feudatárias formadas pelos primeiros "conquistadores" que controlavam os distintos cargos de justiça, governo e comércio locais.

A estreita vinculação de ambas famílias com a gestão do poder político, chave de suas aspirações, faz deste o fio condutor a partir do qual podemos seguir a evolução principal das duas trajetórias. Tanto na periferia de Castilha como na do virreinato do Peru, o político se constitui em um elemento de jogo de poder e promoção social que chamará a atenção de boa parte das elites e famílias das oligarquias urbanas (p. 66, tradução livre).

Outro aspecto muito bem apresentado no livro diz respeito às dispensas matrimoniais que eram solicitadas à igreja para a realização de casamentos consanguíneos, e como essa prática poderia também ser utilizada como forma de estratégia familiar. Os autores do segundo capítulo, Juan Francisco López e María del Carmen Ferreyra discutem que, na realidade, essa não era uma conduta aceita pela Igreja Católica, já que existiam vários impedimentos e, inclusive, graus de parentesco (sanguíneo e espiritual) que deveriam ser respeitados. para que um casamento ocorresse entre membros de uma mesma família. Ainda assim, esse tipo de união era realizada.

Os autores pesquisaram as recorrências de pedidós de dispensas matrimoniais em Múr- cia e Córdoba durante o século XVIII e verificaram as principais características desses pedidos, tanto no Reino como na Colônia. De acordo com eles, no que se refere ao paren-, tesco propriamente dito, as realidades matrimoniais de Múrcia e Córdoba apresentavam traços bem diferenciados. Em Córdoba, a consanguinidade poderia ser considerada como um pilar da hierarquia social existente, através da qual um dos principais objetivos era o de manter uma endogamia racial. Às famílias criollas interessava manter uma "pureza de sangue", possível somente através do parentesco.

Já para o caso de Múrcia, é possível verificar uma realidade mais heterogênea, em que há uma infinidade de alianças e um espaço matrimonial mais amplo. Assim, não havia uma limitação social a partir da etnia, por exemplo, e os casos de casamentos consanguíneos obedeciam a outros parâmetros, relacionados, sobretudo, ao fortalecimento das famílias e aos processos de mobilidade social.

Outro fator interessante de se mencionar diz respeito aos graus de consanguinidade mais recorrentes nas relações cujas dispensas foram solicitadas. Em Córdoba, geralmente os noivos possuíam graus um pouco mais distantes, terceiro e quarto graus de parentesco. Em contrapartida, em Múrcia, foi possível observar casos de parentesco mais próximos, como primeiro e segundo graus, como, por exemplo, o casamento de um tio com uma sobrinha. É possível que essa diferenciação se dê, sobretudo, pelos valores que deveriam ser pagos para se obter a dispensa, que eram mais altos quando se tratava de parentescos mais estreitos. De acordo com os autores, na amostra argentina não houve casos desse tipo, pois "sua localização geográfica não permite burlar a norma. Isso acontece em 
outros territórios americanos, quando se pretende obter dispensa, mas os obstáculos impostos pela Diocese e os altos preços das mesmas, obrigam uma emigração matrimonial" (p. 104, tradução livre).

O livro aqui apresentado nos mostra, a partir de experiencias de pesquisas realizadas em dois países, exemplos e caminhos metodológicos para se trabalhar com História da Família, enfatizando que o papel das famí- lias ultrapassava a vida privada e invadia a esfera pública, onde as estratégias familiares influenciavam a vida social e política da região estudada. Uma vez que a obra se coloca, como tentativa de avanço nos estudos sobre a família, podemos afirmar que tal propósito foi atingido, pois a partir dessa leitura será possível fomentar novas pesquisas que contemplem a perspectiva da História da Família, da Demografia Histórica e até mesmo da História Comparada. 